United Nations Educational Scientific and Cultural Organization and International Atomic Energy Agency

THE ABDUS SALAM INTERNATIONAL CENTRE FOR THEORETICAL PHYSICS

\title{
STRUCTURAL, ELECTRICAL AND OPTICAL PROPERTIES \\ OF COPPER SELENIDE THIN FILMS DEPOSITED BY CHEMICAL BATH DEPOSITION TECHNIQUE
}

\author{
$\mathrm{Al}$ - Mamun \\ Department of Physics, University of Dhaka, Dhaka 1000, Bangladesh, \\ A.B.M.O. Islam ${ }^{1}$ \\ Department of Physics, University of Dhaka, Dhaka 1000, Bangladesh \\ and \\ The Abdus Salam International Centre for Theoretical Physics, Trieste, Italy \\ and \\ A.H. Bhuiyan \\ Department of Physics, Bangladesh University of Engineering and Technology, \\ Dhaka 1000, Bangladesh. \\ MIRAMARE - TRIESTE
}

July 2004

\footnotetext{
${ }^{1}$ Regular Associate of the Abdus Salam ICTP. oislambd@yahoo.com
} 


\begin{abstract}
A low cost chemical bath deposition (CBD) technique has been used for the preparation of $\mathrm{Cu}_{2-\mathrm{x}} \mathrm{Se}$ thin films on glass substrates. Structural, electrical and optical properties of these films were investigated. X-ray diffraction (XRD) study of the $\mathrm{Cu}_{2-\mathrm{x}} \mathrm{Se}$ films annealed at $523 \mathrm{~K}$

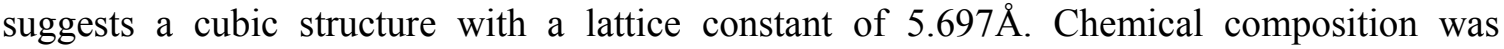
investigated by X-ray photoelectron spectroscopy (XPS). It reveals that absorbed oxygen in the film decreases remarkably on annealing above $423 \mathrm{~K}$. The $\mathrm{Cu} / \mathrm{Se}$ ratio was observed to be the same in as-deposited and annealed films. Both as-deposited and annealed films show very low resistivity in the range of $(0.04-0.15) \times 10^{-5} \Omega-\mathrm{m}$. Transmittance and Reflectance were found in the range of $5-50 \%$ and $2-20 \%$ respectively. Optical absorption of the films results from free carrier absorption in the near infrared region with absorption coefficient of $\sim 10^{8} \mathrm{~m}^{-1}$. The band gap for direct transition, Eg.dir varies in the range of 2.0-2.3 eV and that for indirect transition Eg.indir is in the range of 1.25-1.5 eV.1.
\end{abstract}




\section{Introduction}

Copper selenide is a semiconducting material, which has electrical and optical properties suitable for photovoltaic application. The techniques adopted for deposition of this metal chalcogenide vary from reaction of metallic copper with selenium dissolved in a benzene medium [1] or an aqueous medium [2], flash evaporation [3], vacuum evaporation [4-7], melting of $\mathrm{Cu}$ and $\mathrm{Se}[8,9]$, and electrodeposition [10], to the simplest method of chemical bath deposition (CBD) [11-22]. Copper selenide exists in widely differing crystallographic structures depending on the method of preparation even at room temperature. Okimura and Matsumae deposited $\mathrm{Cu}_{2-\mathrm{x}} \mathrm{Se}$ thin films on to glass substrates by vacuum evaporation method and reported the dc electrical properties. They found p-type conduction with low resistivity. They fabricated $\mathrm{Cu}_{2-\mathrm{x}} \mathrm{Se}$ thin film solar cells, which showed conversion efficiency of about 8.8\% and good stability [5]. Chen et al. used copper selenide as an absorbing layer and reported a $\mathrm{Cu}_{2-\mathrm{x}} \mathrm{Se} / \mathrm{CdS}$ heterojunction solar cell with an efficiency of 5.38\% [7]. Lakshmi et al. reported the depth profiling of as-deposited $\mathrm{Cu}_{3} \mathrm{Se}_{2}$ film $[21,22]$.

During the last two decades, less expensive methods, like chemical and electrochemical conversion, precipitation, ion displacement, electrodeposition and low temperature dip type for the preparation of copper selenide and their characterization have been reported by several authors [1, 2, 8-23]. CBD is a method of growing thin film of certain materials on a substrate immersed in an aqueous bath containing appropriate reagents at temperatures ranging from room temperature to $373 \mathrm{~K}$. It has been identified as one of the techniques for growing $\mathrm{Cu}_{2-\mathrm{x}} \mathrm{Se}$ films at low cost.

The optical properties of interest for solar cell application of a material are reflectance, transmittance, absorptions, emittance and index of refraction [24]. An ideal absorber is one that completely absorbs the incident solar energy and does not emit any radiation. In this experiment copper selenide thin films with various ratios of copper and selenium were deposited onto a glass substrate using low cost CBD method. In general, the growth of good quality semiconductor thin films by CBD technique proceeds at a slow pace. This technique is ideally suited for producing uniform films with thicknesses of 0.05-0.3 $\mu \mathrm{m}$ in most cases. Recently, we have reported the brief result on the characterization of copper selenide thin films deposited by CBD technique [25]. This paper describes the detail results observed by XPS, Xray diffraction (XRD), electrical, and optical investigations on the $\mathrm{Cu}_{2-\mathrm{x}} \mathrm{Se}$ film prepared by CBD. An attempt is made here to correlate the observed results. 


\section{Experimental details}

The chemicals used for the preparation of thin films were LR grade (Merck) cupric chloride di-hydrate $\left(\mathrm{CuCl}_{2}, 2 \mathrm{H}_{2} \mathrm{O}\right)$, selenium powder of $99.99 \%$ purity, sodium sulfite $\left(\mathrm{Na}_{2} \mathrm{SO}_{3}\right)$, tri-ethanol amine (TEA) and ammonium hydroxide $\left(\mathrm{NH}_{4} \mathrm{OH}\right)$. First, sodium selenosulfate was made by refluxing fine selenium powder with sodium sulfite solutions for about 30 minutes at $393 \mathrm{~K}$ by stirring in a beaker. A constant stirring machine with a constant temperature bath was used during the reaction. Secondly, $\mathrm{CuCl}_{2} 2 \mathrm{H}_{2} \mathrm{O}$ solution was mixed with $\mathrm{NaSeSO}_{3}$ at constant stirring. $10 \mathrm{ml}$ TEA $(0.1 \mathrm{M})$ was added to this solution. $\mathrm{NH}_{4} \mathrm{OH}$ was used to adjust the $\mathrm{pH}$ of the reaction bath. Microscope glass slides of $76 \times 26 \times 1 \mathrm{~mm}^{3}$ were used as substrates. The substrates were cleaned with detergent and distilled water, and were kept in $\mathrm{H}_{2} \mathrm{SO}_{4}$ for about $1 \mathrm{~h}$. Then the substrates were rinsed with distilled water and were dried in air prior to film deposition. The substrates were then immersed vertically into the deposition bath against the wall of the beaker containing the reaction mixture. The deposition was allowed to proceed at room temperature for different time durations from 15 to 180 minutes. After deposition, the glass slides were taken out from the bath, washed with distilled water and were dried in blowing air. All the samples were annealed in air at higher temperatures up to $523 \mathrm{~K}$ to observe annealing effects.

Identification of the deposited film material was carried out by a Philips X'Pert X-ray diffractometer where the powder diffraction technique was used with a primary beam power of $40 \mathrm{kV}$ and $30 \mathrm{~mA}$ for $\mathrm{Cu} \mathrm{K} \alpha$ radiation. The XPS technique was employed for the analysis of the chemical composition of the films. XPS experiments were performed in a VG ESCALAB MkII photoelectron spectrometer, at Surface Science Laboratory, TU Darmstadt, Germany, the ultra-high vacuum (UHV) chamber is directly connected to a home-made deposition chamber by a sample transfer system (base pressure $\sim 10^{-9} \mathrm{mbar}$ ). Electrons were excited with an X-ray source $(\mathrm{Mg} \mathrm{K} \alpha \mathrm{h} v=1253.6 \mathrm{eV})$. The samples for XPS measurements were annealed in UHV at 473 and $523 \mathrm{~K}$ for $30 \mathrm{~min}$.

A laboratory dc power supply (GPR-3020, GW, Taiwan), an electrometer Keithley 614 (Keithley Instrument Inc. USA) and a digital multimeter (GDM-354A, GW, Taiwan) were used for electrical measurements. Two points $(1.5 \mathrm{~mm}$ width and $13.6 \mathrm{~mm}$ length) on the surface of the film $45 \mathrm{~mm}$ apart were made with silver paste for electrical contact.

The optical measurements were performed using a UV-121V spectrophotometer (Shimadzu Corp., Japan). The thickness of the films was determined by using data pack in spectrophotometer. Using data pack for the determination of the thickness of the sample is a completely automatic process. 


\section{Results and discussion}

\subsection{Growth of the films}

The temperature dependence of film formation has been shown in Fig.1. In all cases, the film growth sets in after an initial nucleation period of about 5-10 minutes. With the increase of bath temperature up to $363 \mathrm{~K}$, the rate of deposition of films decreases due to an increase in the kinetic energy of the reacting ions, i.e., an increase in the frequency of collisions among the ions. Powdery deposits and lack of specular reflection usually accompany higher deposition rate and higher film thickness. The films start peeling off from the substrates at higher bath temperatures (above 373K). Moreover, at higher bath temperatures, the deposition is not uniform. Hence, deposition at room temperature is always preferred. In this study, good samples of $\mathrm{Cu}_{2-\mathrm{x}} \mathrm{Se}$ thin film deposited for 1 hour at room temperature of thickness between 0.12 and $0.18 \mu \mathrm{m}$ were characterized, and these parameters are the same for all the samples used in the present measurements.

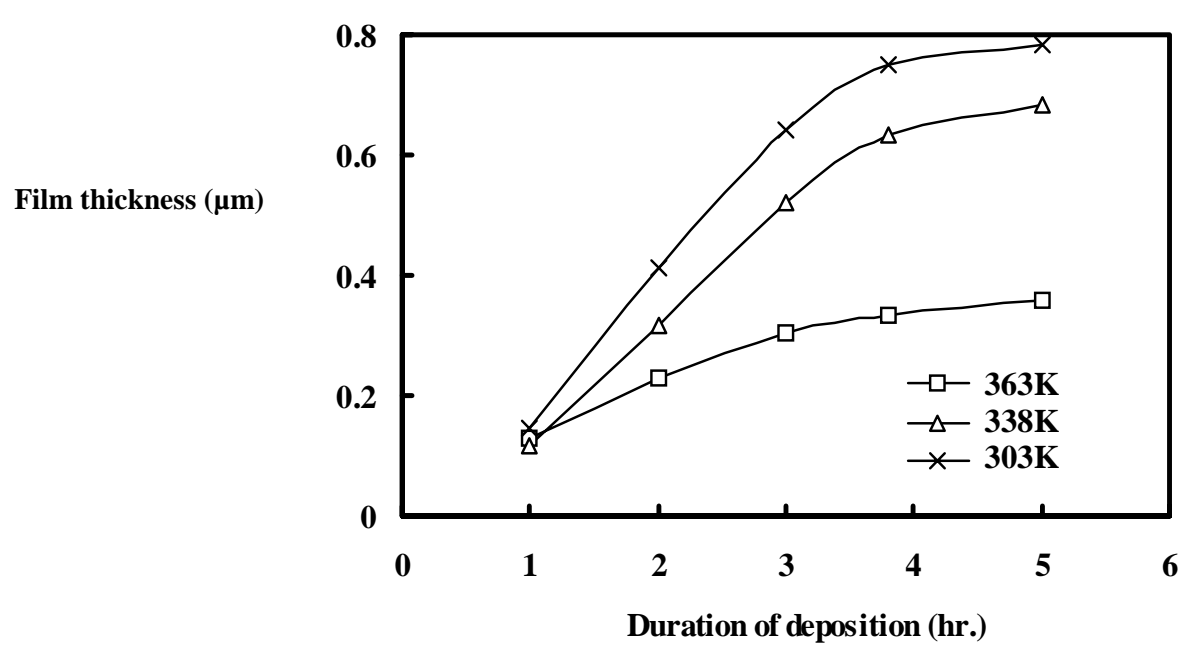

Figure 1. Film thickness versus deposition time.

\subsection{Structural characterization}

Figure 2 shows the XRD pattern of $\mathrm{Cu}_{2-\mathrm{x}} \mathrm{Se}$ thin film. In the figure, (a) is for the asdeposited $\mathrm{Cu}_{2-\mathrm{x}} \mathrm{Se}$ thin film and (b) for the $\mathrm{Cu}_{2-\mathrm{x}} \mathrm{Se}$ thin film followed by annealing at $523 \mathrm{~K}$ in air. Lots of noise is observed in the XRD pattern may be due to the growth of disordered film. From this pattern it shows that no well-defined peak was found and no well-defined plane was obtained in the case of as-deposited films, which suggests that the as-deposited films were 
disordered. A slight tendency of increasing peaks is found with annealing at an angle $2 \theta=$ $27.30,45.35$ and $52.78^{\circ}$. The intensity of the observed peaks is very low, but becomes stronger after annealing at $523 \mathrm{~K}$.

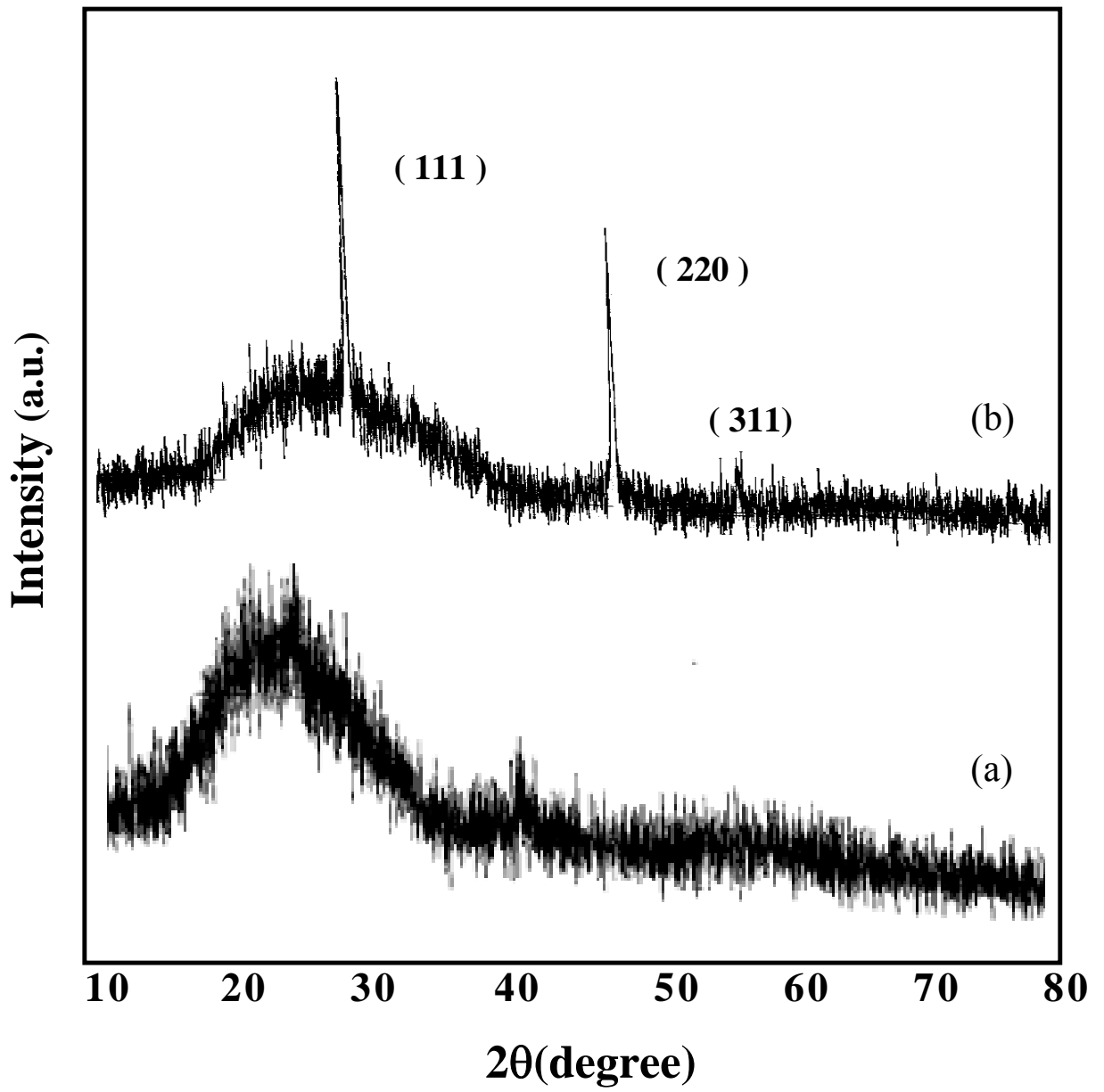

Figure 2. X-ray diffraction pattern of (a) as-deposited $\mathrm{Cu}_{2-\mathrm{x}} \mathrm{Se}$ thin film and (b) $\mathrm{Cu}_{2-\mathrm{x}} \mathrm{Se}$ thin film followed by annealing at $523 \mathrm{~K}$ in air for $1 \mathrm{hr}$.

Figure $2 \mathrm{~b}$ shows well-defined peaks suggesting the formation of crystalline film due to annealing at higher temperatures. A comparison of the observed pattern with the standard JCPDS cards shows that the annealed samples with above condition possess a structure matching the mineral spherulites (JCPDS 26-512), $\mathrm{Cu}_{2-\mathrm{x}} \mathrm{Se}$ with $\mathrm{x}=0.2$ which belongs to the cubic system with $a=5.697 \AA$. The observed peak positions of the annealed sample are in agreement with those due to reflection from (111), (220) and (311) planes of the reported structure of $\mathrm{Cu}_{2-\mathrm{x}} \mathrm{Se}$ thin film. The same reflection plane and crystal structure were observed for as-deposited $\mathrm{Cu}_{2-\mathrm{x}} \mathrm{Se}$ thin films prepared by $\mathrm{CBD}$ method using $\mathrm{CuSO}_{4}$ and tri-sodium citrate solution $[19,21,22]$. 


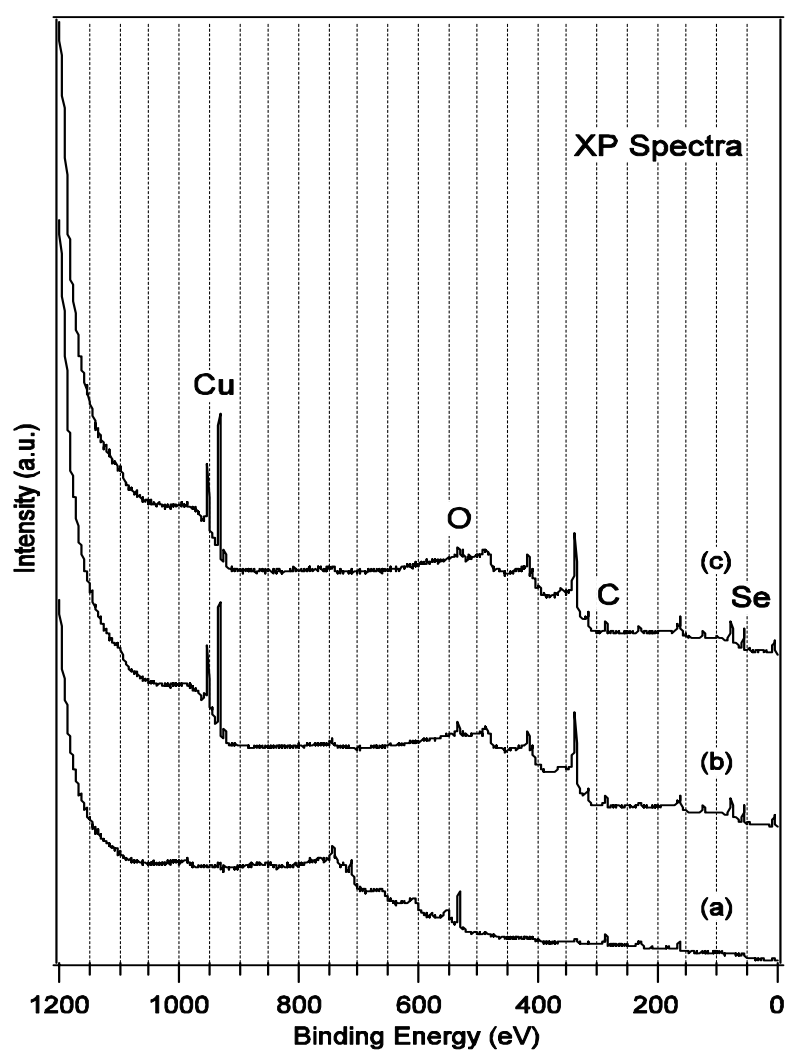

Figure 3. XPS spectra of $\mathrm{Cu}_{2-\mathrm{x}}$ Se thin film: (a) as-deposited, (b) after annealing at $473 \mathrm{~K}$ for $30 \mathrm{~min}$, (c) after annealing at $523 \mathrm{~K}$ for $30 \mathrm{~min}$. The annealing is performed in UHV chamber.

\subsection{XPS measurement}

The XP spectra of different copper selenide thin films are presented in Fig. 3. In the figure, spectrum $a$ represents the as-deposited sample, spectrum $b$ represents the sample annealed at $473 \mathrm{~K}$ and spectrum $c$ represents the sample annealed at $523 \mathrm{~K}$. It is observed that the as-deposited film is mostly covered with oxygen and carbon (spectrum $a$ ), whereas the peak intensities of $\mathrm{Cu}$ and $\mathrm{Se}$ are very weak. It is common for the chemically-deposited sample to be contaminated with oxygen (at $531 \mathrm{eV}$ ) and carbon (at $285 \mathrm{eV}$ ) from the environment as the sample was exposed to the environment during preparation. The peaks corresponding to $\mathrm{Cu}$ and Se became prominent in the sample annealed at $473 \mathrm{~K}$ (spectrum $b$ ) and after annealing at $523 \mathrm{~K}$, the intensity of $\mathrm{Cu}$ and Se peaks (spectrum $c$ ) increased further, thereby indicating further lowering of oxygen contamination. Upon annealing above $573 \mathrm{~K}$, Se starts to desorb from the surface (data are not shown), which means that the copper selenide film remains stable up to the temperature of about $573 \mathrm{~K}$. It was also observed that colour of the film was changed from greenish to orange due to annealing. This means that the as-deposited film is 
contaminated by oxygen, and oxygen contamination is removed during annealing process. The amount of oxygen decreases significantly but Se also starts to decrease due to annealing above $573 \mathrm{~K}$. With a $473 \mathrm{~K}$ anneal, the colour becomes greenish orange and at $523 \mathrm{~K}$, the colour changes to fully orange, which does not change on annealing above $573 \mathrm{~K}$.
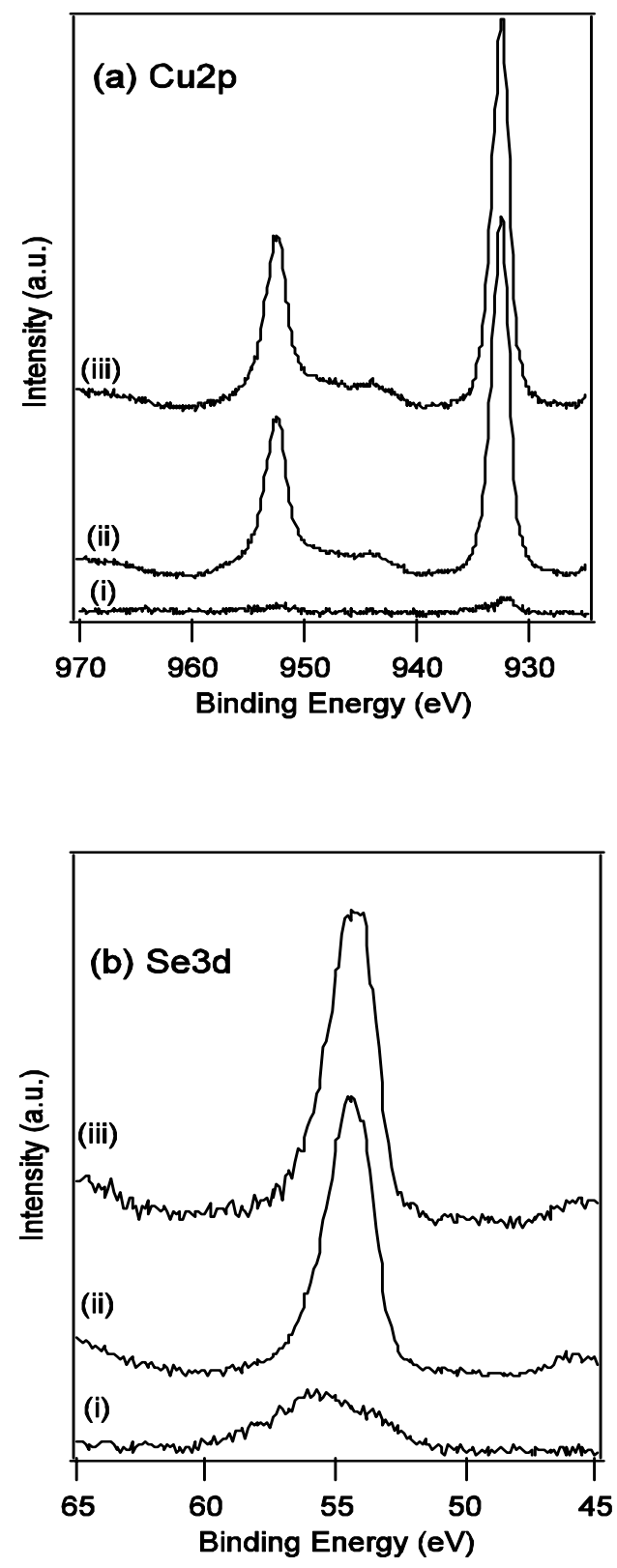

Figure 4. Core-level XPS spectra of $\mathrm{Cu}_{2-\mathrm{x}} \mathrm{Se}$ thin film: (a) $\mathrm{Cu} 2 p^{1 / 2}$ level (i) as-deposited, (ii) after annealed at $473 \mathrm{~K}$ for $30 \mathrm{~min}$, (iii) after annealed at $523 \mathrm{~K}$ for $30 \mathrm{~min}$ and (b) Se $3 d$ level (i) asdeposited, (ii) after annealed at $473 \mathrm{~K}$ for $30 \mathrm{~min}$, (iii) after annealed at $523 \mathrm{~K}$ for $30 \mathrm{~min}$. The annealing is performed in UHV chamber. 
The core level spectra of $\mathrm{Cu} 2 p$ and Se $3 d$ are shown in Fig. 4. In figure 4, the $\mathrm{Cu} 2 p$ core level spectra and the Se $3 d$ core level spectra are shown for the as-deposited sample, and for the samples annealed at 473 and $523 \mathrm{~K}$. The $\mathrm{Cu} 2 p$ and Se $3 d$ peaks of the as-deposited sample are very weak due to the $\mathrm{O}$ and $\mathrm{C}$ contamination. Both the $\mathrm{Cu} 2 p$ and $\mathrm{Se} 3 d$ peaks become prominent after annealing, thereby indicating reduction of contamination by annealing. The binding energies of $\mathrm{Cu} 2 p^{1 / 2}$ and Se $3 d$ peaks of as-deposited sample are observed to be at 932.0 and $55.4 \mathrm{eV}$ respectively. The binding energy of both the $\mathrm{Cu} 2 p^{1 / 2}$ and Se $3 d$ peaks are changed to 932.4 and $54.4 \mathrm{eV}$ respectively, due to annealing at $473 \mathrm{~K}$. The binding energy of $\mathrm{Cu} 2 p^{3 / 2}$ peak of as-deposited and annealed sample is observed to be at 952.0 and $952.4 \mathrm{eV}$ respectively. It is also observed that the peak positions of $\mathrm{Cu} 2 p^{1 / 2}$ and $\mathrm{Se} 3 d$ are not changed any more by annealing at $523 \mathrm{~K}$. The peak area of $\mathrm{Cu} 2 p$ and $\mathrm{Se} 3 d$ has been calculated and the $\mathrm{Cu} / \mathrm{Se}$ ratio is estimated to be about 1.8 for all the samples.

\subsection{Electrical properties}

Figure 5 shows the I-V characteristic curves for the film deposited at room temperature and that followed by annealing at $523 \mathrm{~K}$ for one hour. The calculated resistivity is found in the range from $0.05 \times 10^{-5}$ to $0.15 \times 10^{-5} \Omega-\mathrm{m}$. The I-V characteristic has been studied over the range from $5 \mathrm{mV}$ to $14 \mathrm{~V}$. An ohmic contact is observed in as-deposited and annealed samples.

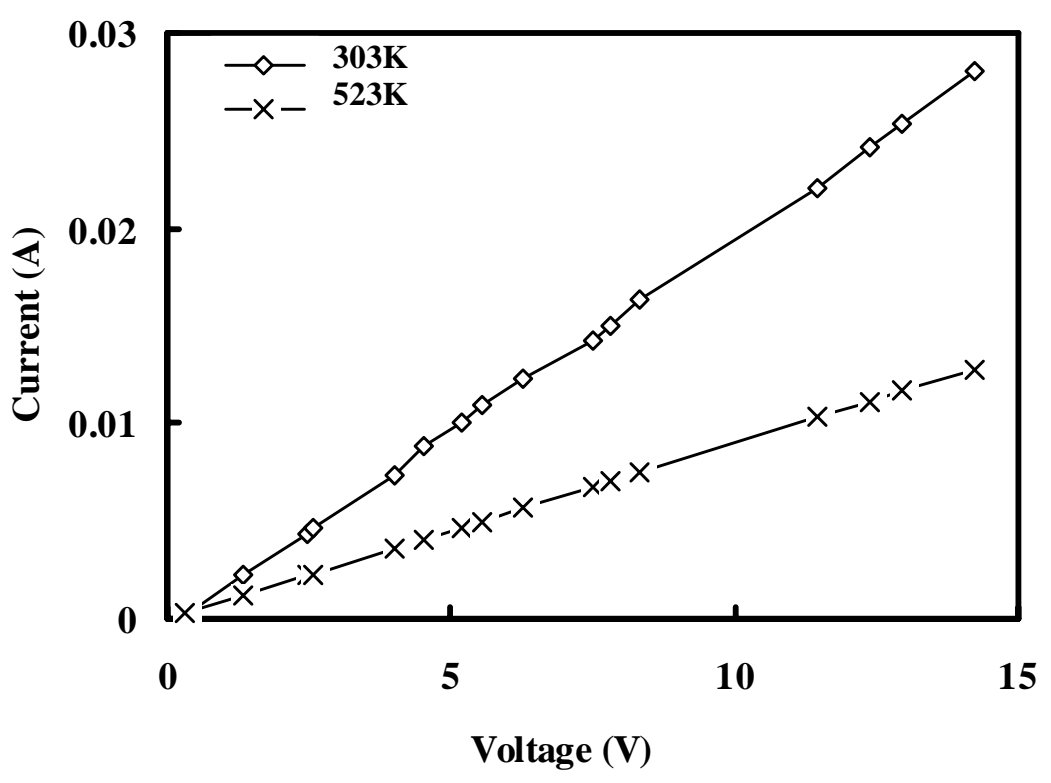

Figure 5. Current-voltage curve for $\mathrm{Cu}_{2-\mathrm{x}} \mathrm{Se}$ thin film: (a) asdeposited, (b) annealed at $523 \mathrm{~K}$ for $1 \mathrm{hr}$. 
Figure 6 represents the change of room temperature resistivity with the increase of annealing temperature. Initially the resistivity decreases slowly with the increase of annealing temperature up to $473 \mathrm{~K}$ and then increases rapidly. As observed in XPS, the surface of the asdeposited $\mathrm{Cu}_{2-\mathrm{x}} \mathrm{Se}$ is mostly covered with oxygen. In as-deposited and samples annealed at lower temperatures ionization take place on the surface owing to the presence of oxygen resulting in lower resistivity because of the interaction of the ionic current with the electronic current. However, for the sample annealed above 473K, the ionic contribution becomes less due to desorption of oxygen from the surface. As a result, the resistivity increases rapidly.

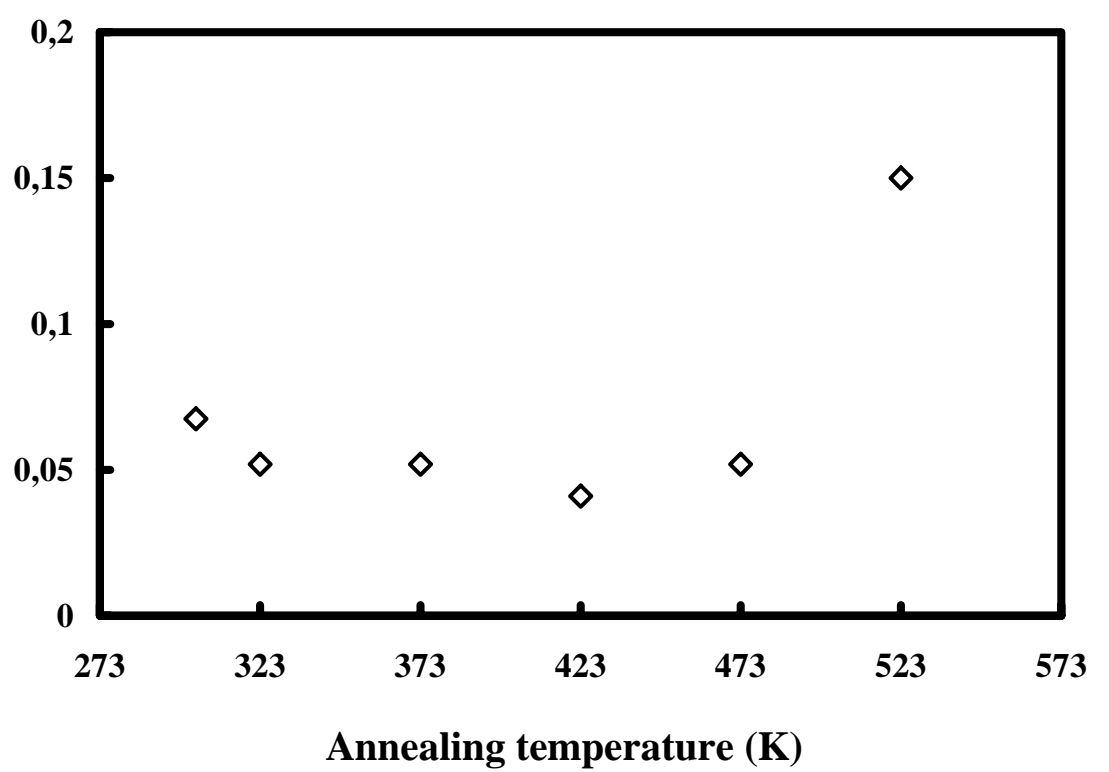

Figure 6. Variation of resistivity with annealing temperature for $\mathrm{Cu}_{2-\mathrm{x}} \mathrm{Se}$ thin films of thickness $0.16 \mu \mathrm{m}$.

\subsection{Optical absorption spectra}

The variation of transmittance $\left(\mathrm{T} \%\right.$ ) of $\mathrm{Cu}_{2-\mathrm{x}} \mathrm{Se}$ thin films with wavelength $\lambda$ at different annealing temperatures is shown in Fig. 7. Transmittance is obtained to be about 3$50 \%$ in the wavelength range $400-1100 \mathrm{~nm}$. A gradual decrease in transmittance upon annealing is observed in the lower wavelength region, which may be due to absorption by free carriers in the degenerate films. The peak values of transmission spectra are seen at around $820-880 \mathrm{~nm}$. The absorption starts around this wavelength and the transmittance becomes very low at $\lambda<500 \mathrm{~nm}$. In the near infrared, the transmittance decreases with the increase of wavelength for samples annealed up to $473 \mathrm{~K}$. For the sample annealed at $523 \mathrm{~K}$, the 
transmittance is observed to be less dependent on $\lambda$ above $900 \mathrm{~nm}$. The decrease of transmittance in the lower wavelength region is due to free carrier absorption.

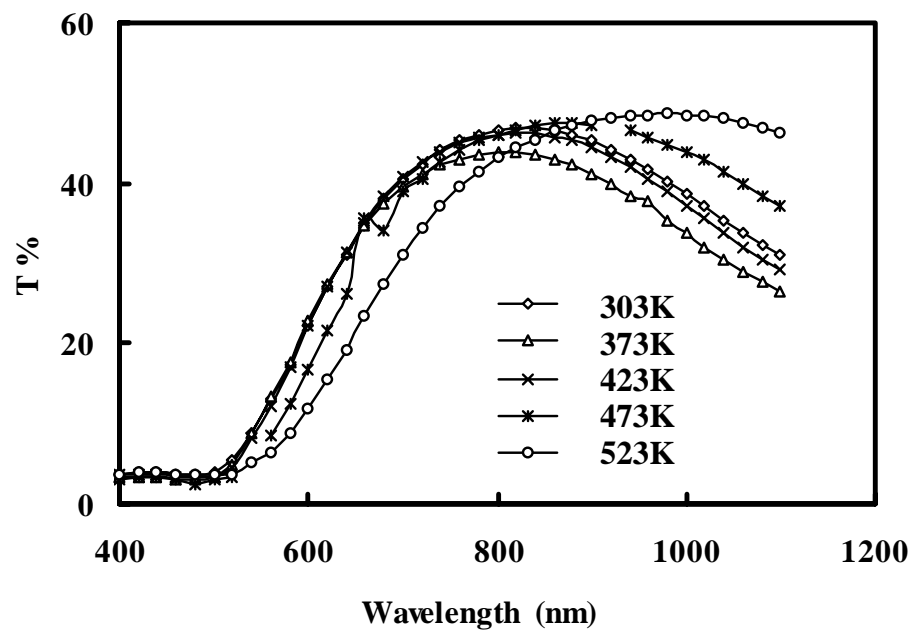

Figure 7. The optical transmittance spectra of $\mathrm{Cu}_{2-\mathrm{x}} \mathrm{Se}$ thin film: as-deposited films were annealed at different temperature in the range $303-523 \mathrm{~K}$.

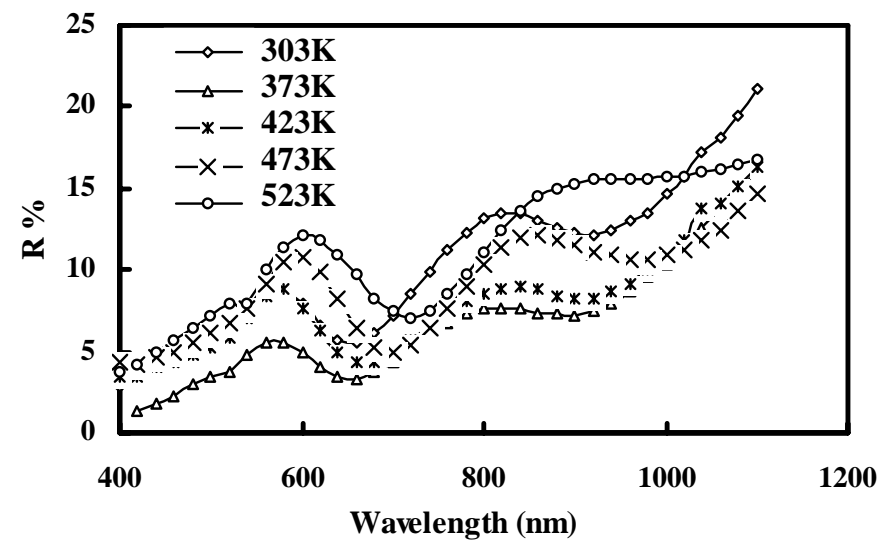

Figure 8. The optical reflectance spectra of $\mathrm{Cu}_{2-\mathrm{x}} \mathrm{Se}$ thin film: asdeposited films were annealed at different temperature in the range $303-523 \mathrm{~K}$.

Figure 8 represents the variation of reflectance $(\mathrm{R} \%)$ of $\mathrm{Cu}_{2-\mathrm{x}} \mathrm{Se}$ thin films with $\lambda$ for samples annealed at different temperatures. Reflectance is found to be about $4-20 \%$ in the wavelength region $400-1100 \mathrm{~nm}$. Reflectance becomes very small at around $400 \mathrm{~nm}$. It is observed in the $\mathrm{R}(\%)$ vs $\lambda$ curves that there are two peaks around $575-600 \mathrm{~nm}$ and $800 \mathrm{~nm}$. Both the peaks shift to higher wavelength with annealing temperature. The second $\mathrm{R}(\%)$ peak 
appears at the same wavelength region where the transmittance peak appears in Fig. 7. Similar behavior was reported for $\mathrm{Cu}_{2-\mathrm{x}} \mathrm{Se}$ thin films prepared by $\mathrm{CBD}$ technique with $\mathrm{CuSO}_{4}, 5 \mathrm{H}_{2} \mathrm{O}$ at $298 \mathrm{~K}$ for 8 hours [20]. The behaviour of high transmittance and low reflectance obtained in this experiment may make the materials suitable as an electro-conductive window coating. Peak wavelength values of transmittance and reflectance are listed in Table 1.

\begin{tabular}{|c|c|c|c|c|c|c|c|c|}
\hline \multirow{3}{*}{$\begin{array}{l}\text { Temperature } \\
\text { (K) }\end{array}$} & \multirow{3}{*}{$\begin{array}{c}\text { Direct } \\
\text { band gap } \\
(\mathrm{eV})\end{array}$} & \multirow{3}{*}{$\begin{array}{c}\text { Indirect } \\
\text { band gap } \\
(\mathrm{eV})\end{array}$} & \multirow{2}{*}{\multicolumn{2}{|c|}{$\begin{array}{c}\text { Peak value for } \\
\qquad \%\end{array}$}} & \multicolumn{4}{|c|}{ Peak value for $\mathrm{R} \%$} \\
\hline & & & & & \multicolumn{2}{|c|}{$1^{\text {st }}$ peak } & \multicolumn{2}{|c|}{$2^{\text {nd }}$ peak } \\
\hline & & & $\lambda(\mathrm{nm})$ & $\mathrm{T} \%$ & $\lambda(\mathrm{nm})$ & $\mathrm{R} \%$ & $\lambda(\mathrm{nm})$ & $\mathrm{R} \%$ \\
\hline 303 & 2.3 & 1.3 & 820 & 46.9 & 580 & 8.6 & 820 & 13.5 \\
\hline 373 & 2.3 & 1.4 & 820 & 43.8 & 560 & 5.6 & 820 & 7.7 \\
\hline 423 & 2.3 & 1.5 & 840 & 46.2 & 580 & 8.8 & 840 & 9.0 \\
\hline 473 & 2.1 & 1.4 & 880 & 47.5 & 600 & 10.8 & 860 & 12.1 \\
\hline 523 & 2.0 & 1.25 & 980 & 48.6 & 600 & 12.1 & 940 & 15.6 \\
\hline
\end{tabular}

Table 1. Direct and indirect band gap values, peak wavelength values of $\mathrm{T} \%$ and $\mathrm{R} \%$ and their corresponding maximum $\mathrm{T} \%$ and $\mathrm{R} \%$ values for different annealing temperatures.

The absorption coefficient $(\alpha)$ at different wavelengths was calculated using the corrected transmittance values from $\alpha=(1 / t) \ln \left(100 / T_{\text {corr. }}\right)$, where corrected transmittance, $T_{\text {corr., }}$ can be obtained using the relation Tcorr. $=\{\mathrm{T}(\%) /(100-\mathrm{R}(\%))\} \times 100[19,26]$. The $\alpha \mathrm{vs} h v$ curve is presented in Fig. 9. It is seen that $\alpha$ is non-linear with $h v$. A maximum of $10^{8} \mathrm{~m}^{-1}$ absorption coefficient is observed around $2.5 \mathrm{eV}$. Using the optical spectra, the band gap values for the films were estimated. The direct and indirect band gap values are obtained from the plots of $(\alpha h v)^{2}$ and $(\alpha h v)^{1 / 2}$ respectively, against photon energy $h v(\mathrm{eV})$. Such plots for the films (asdeposited and annealed) are shown in Figs. 10 and 11 for the determination of direct and indirect band gaps. Extrapolating the straight-line part of the curves in these figures to the energy axis, where $(\alpha h v)^{2}=0$, gives the values of band gap for direct transitions (Eg.dir) and to where $(\alpha h v)^{1 / 2}=0$ gives the values of band gap for indirect transitions (Eg.indir). The Eg.dir varies in the range of 2.0-2.3 eV and the Eg.indir is in the range of 1.25-1.5 eV for all samples from as-deposited to all annealed samples up to 523K. These kinds of values of band gap are reported for $\mathrm{Cu}_{2-\mathrm{x}} \mathrm{Se}$ thin film deposited by $\mathrm{CBD}$ technique using $\mathrm{CuSO}_{4}$ and $\mathrm{N}, \mathrm{N}-$ dimethylselenourea $[19,21,22]$. It is observed that both direct and indirect band gap values of 
as-deposited samples are less compared with those of the annealed samples. The increase of band gap due to annealing may be understood by the improvement of crystallinity of the asdeposited film on annealing as observed in XRD.

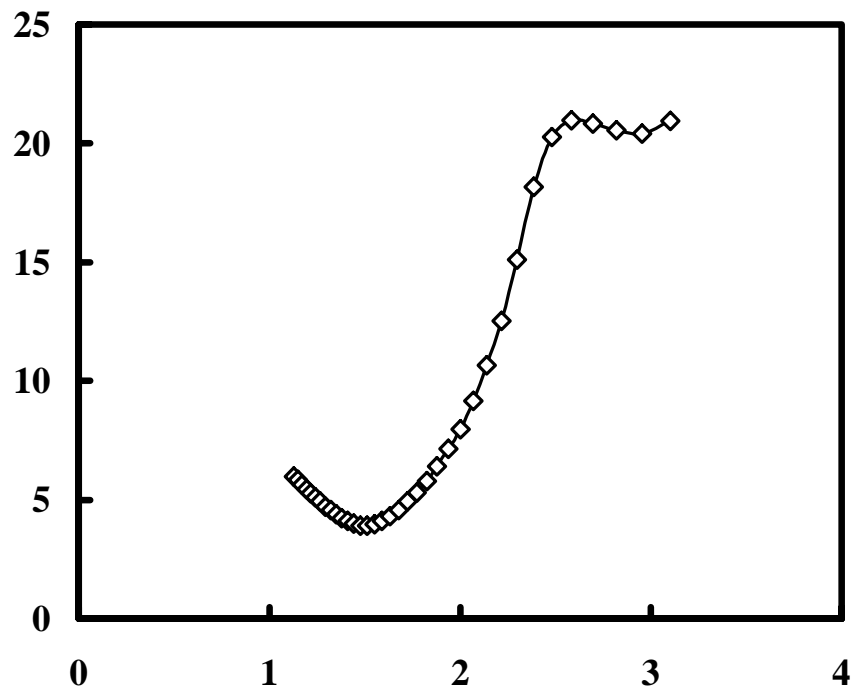

Figure 9. $\alpha$ versus $h v$ curve for as-deposited $\mathrm{Cu}_{2-\mathrm{x}} \mathrm{Se}$ thin film.

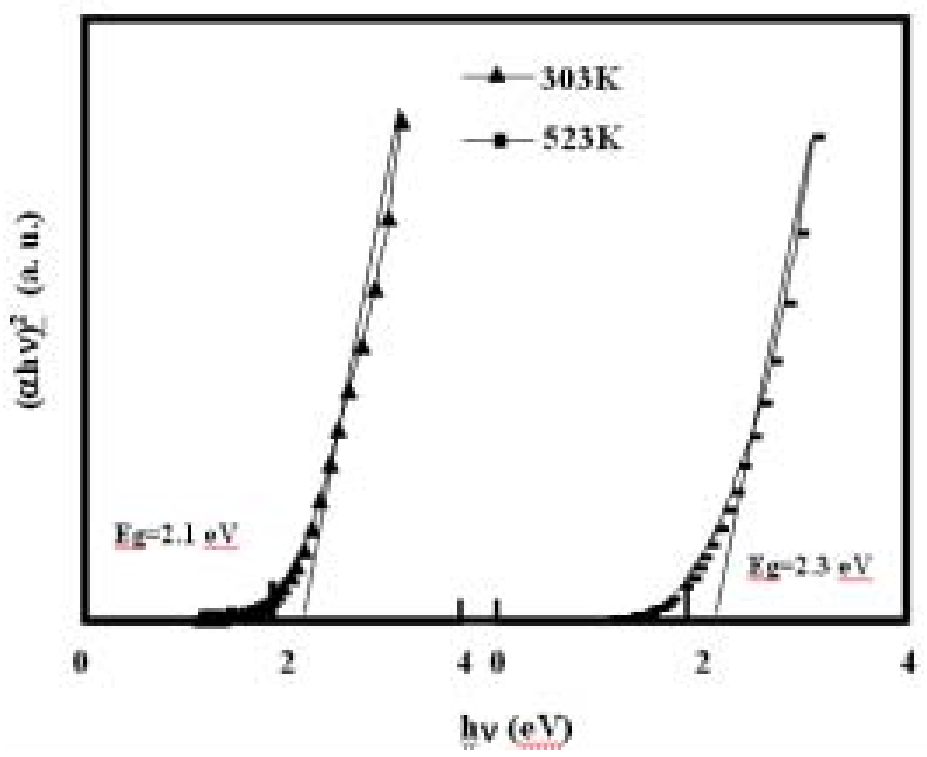

Figure 10. $(\alpha h v)^{2}$ vs hv plots of $\mathrm{Cu}_{2-\mathrm{x}} \mathrm{Se}$ thin film: (a) asdeposited, (b) annealed at $523 \mathrm{~K}$ for $1 \mathrm{hr}$. 


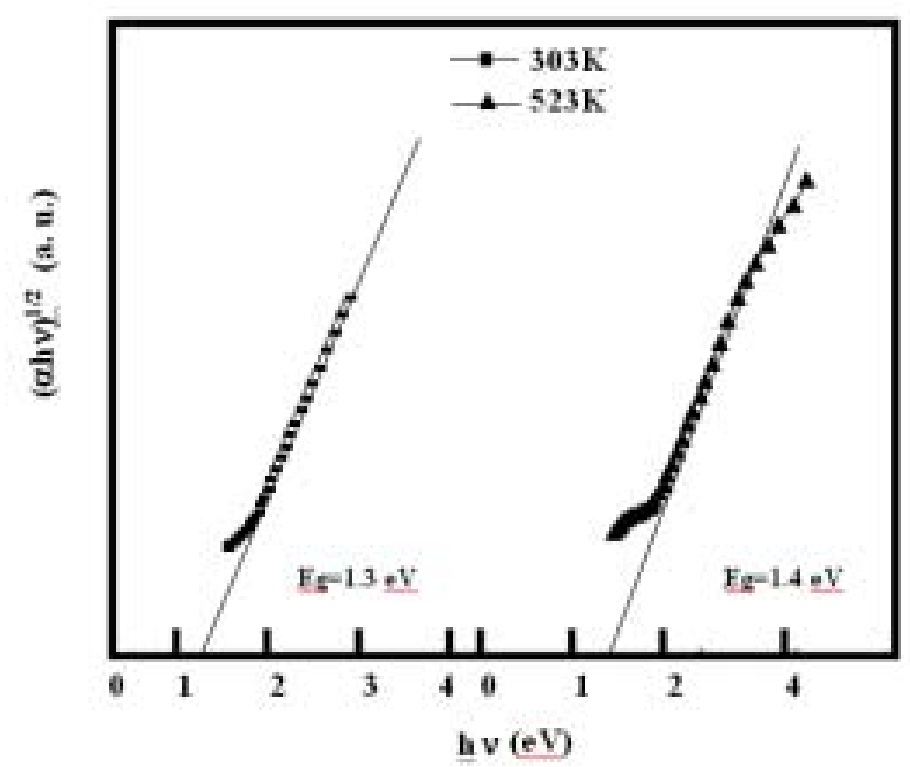

Figure 11. $(\alpha h v)^{1 / 2}$ vs hv plots of $\mathrm{Cu}_{2-\mathrm{x}} \mathrm{Se}$ thin film:

(a) as-deposited, (b) annealed at $523 \mathrm{~K}$ for $1 \mathrm{hr}$.

\section{Conclusions}

A thin film of copper selenide of composition $\mathrm{Cu}_{1.8}$ Se of cubic structure with a lattice constant of $5.697 \AA$ was deposited from chemical baths using sodium selenosulfate. It is found that as-deposited samples and films annealed up to $523 \mathrm{~K}$ have low resistivity between $0.04 \times 10^{-5}$ and $0.15 \times 10^{-5} \Omega-\mathrm{m}$. Optical absorption in the films are found from free carrier absorption in the near infrared region with a maximum absorption coefficient of $\sim 10^{8} \mathrm{~m}^{-1}$. The band gap for direct transitions, Eg.dir, varies in the range 2.0-2.3 eV and that for indirect transition, Eg.indir, is in the range $1.25-1.5 \mathrm{eV}$.

\section{Acknowledgments}

The authors are grateful to the Director and staff of Semiconductor Technology Research Center (STRC) for providing laboratory facilities. We acknowledge the financial support given by Bose Center for Advanced Study and Research in Natural Science, University of Dhaka, Bangladesh. A.B.M.O.I is thankful to Prof. W. Jaegermann, TU Darmstadt, Germany for allowing his laboratory to do the XPS. This work was partially carried out within the framework of the Associateship Scheme of the Abdus Salam International Centre for Theoretical Physics (AS ICTP), Trieste, Italy. Financial support from Swedish International Development Cooperation Agency (SIDA) is also acknowledged. 


\section{References}

1. S. G. ELLIS, J. Appl. Phys. 38 (1967) 2906.

2. $\quad$ S. K. HARAM and K. S. V. SANTHANAM, Thin Solid Films 238 (1994) 21.

3. B. TELL and J. J. WIEGAND, J. Appl. Phys. 48 (1977) 5321.

4. R. B. SHAFIZADE, I. V. IVANOVA and M. M. KAZINETS, Thin Solid Films 55 (1978) 211.

5. H. OKIMURA and T. MATSUMAE, Thin Solid Films 71 (1980) 53.

6. A. M. HERMAN and L. FABICK, J. Cryst. Growth 61 (1983) 658.

7. W. S. CHEN, J. M. STEWART and R. A. MICKELSON, Appl. Phys. Lett. 46 (1985) 1095.

8. K. YAKAMOTO and S. KASHIDA, J. Solid State Chem. 93 (1991) 202.

9. M. A. KORZHUEV, V. F. BANKINA, L. G. KOROLKOVA, G. B. SHEINA and E. A. OBRAZTSOVA, Phys. Status Solidi A 123 (1991) 131.

10. S. MASSACCESI, S. SANCHEZ and J. VEDEL, J. Electrochem. Soc. 140 (1993) 2540.

11. A. MONDAL and P. PRAMANIK, J. Solid State Chem. 47 (1983) 81.

12. A. MONDAL and P. PRAMANIK, J. Solid State Chem. 55 (1984) 116.

13. G. K. PADAM, Thin Solid Films 150 (1987) L89.

14. C. A. ESTRADA, P. K. NAIR, M. T. S. NAIR, R. A. ZINGARO and E. A. MEYERS, J. Electrochem. Soc. 141 (1994) 802.

15. I. GROZDANOV, Synth. Mat. 63 (1994) 213.

16. I. GROZDANOV, Semicond. Sci. Technol. 9 (1994) 1234.

17. C. LEVY-CLEMENT, M. NEUMANN-SPALLART, S. K. HARAM and K. S. V. SANTHANAM, Thin Solid Films 302 (1997) 12.

18. P. K. NAIR, M. T. S. NAIR, V. M. GARCÍA, O. L.ARENAS, Y. PEÑA, A. CASTILlO, I. T. AYALA, O. GOMEZDAZA, A. SÁNCHEZ, J. CAMPOS, H. HU, R. SUÁREZ and M. E. RINCÓN, Sol. Energy Mater. Sol. Cells 52 (1998) 313.

19. V. M. GARCÍA, P. K. NAIR and M. T. S. NAIR, J. Cryst. Growth 203 (1999) 113.

20. P. K. NAIR, V. M. GARCÍA, O. GOMEZ-DAZA and M. T. S. NAIR, Semicond. Sci. Technol. 16 (2001) 855.

21. M. LAKSHMI, K. BINDU, S. BINI, K. P.VIJAYKUMAR, C. SUDHA KARTHA, T. ABE and Y. KASHIWABA, Thin Solid Films 370 (2000) 89.

22. M. LAKSHMI, K. BINDU, S. BINI, K. P. VIJAYKUMAR, C. SUDHA KARTHA, T. ABE and Y. KASHIWABA, Thin Solid Films 386 (2001) 127.

23. V. M. BHUSE, P. P. HANKARE, K. M. GARADKAR and A. S. KHOMANE, Mater. Chem. Phys. 80 (2003) 82.

24. H. P. GARG, in "Treatise on Solar Energy, Volume-1, Fundamental of Solar Energy" (A Wiley Inter Science Publication, New York, 1982).

25. AL-MAMUN AND A. B. M. O. ISLAM, Appl. Surf. Sci. (in press).

26. G. HODES, A. A. YARON, F. DECKER and P. MOTISUKE, Phys. Rev. B 36 (1987) 4215. 